\title{
Pyrotinib In The Treatment of Women With Advanced HER2- Positive Breast Cancer: A Multicenter, Prospective, Real-World Study
}

\section{Lili Zhang}

Jiangsu Cancer Hospital \& Jiangsu Institute of Cancer Research \& The Affiliated Cancer Hospital of Nanjing Medical University

\section{Xiaohong Wu}

Affiliated Hospital of Jiangnan University

Jun Zhou

the First People's Hospital of Lianyungang

Mingzhen Zhu

the Second People's Hospital of Lianyungang

\section{Hao Yu}

Zhenjiang First People's Hospital

\section{Yusong Zhang}

the Second Affiliated Hospital of Soochow University

\section{Yutian Zhao}

Affiliated Hospital of Jiangnan University

\section{Zhengxiang Han}

the Affiliated Hospital of Xuzhou Medical University

\section{Yujiang Guo}

Wuxi People's Hospital

\section{Xiaoqing Guan}

Suqian People's Hospital of Nanjing Drum- Tower Hospital Group

\section{Xufen Wang}

the Third Affiliated Hospital of Soochow University, the First People's Hospital of Changzhou

Hong Xu

the First Affiliated Hospital of Soochow University

Li Sun

Xuzhou Central Hospital

Jiaxin Zhang

the Affiliated Hospital of Xuzhou Medical University

\section{Min Zhuang}

the First People's Hospital of Lianyungang 


\section{Li Xie}

Nanjing Drum Tower Hospital, the Affiliated Hospital of Nanjing University Medical School

\section{Shiyou Yu}

Suzhou Municipal Hospital, Affiliated Suzhou Hospital of Nanjing Medical University

\section{Ping Chen}

Yancheng No.1 People's Hospital

Jifeng Feng ( $\square$ lyt15950553165@163.com )

Jiangsu Cancer Hospital \& Jiangsu Institute of Cancer Research \& The Affiliated Cancer Hospital of Nanjing Medical University

\section{Research Article}

Keywords: Pyrotinib, breast cancer, HER2, brain metastasis

Posted Date: May 20th, 2021

DOI: https://doi.org/10.21203/rs.3.rs-505602/v1

License: (a) (i) This work is licensed under a Creative Commons Attribution 4.0 International License. Read Full License 


\section{Abstract}

Background: HER2-positive breast cancer was aggressive, resulting in a poorer prognosis. This multicenter study analyzed the real-world data of women treated with pyrotinib-based therapy, aiming to describe their characteristics, treatment regimens, and to investigate the clinical outcomes.

Patients and Methods: A total of 141 patients with HER2-positive breast cancer were enrolled from February 2019 to April 2020. Last follow-up time was February 2021. All patients were treated with pyrotinib-based therapy in 21-day cycles. The primary endpoint was progression-free survival (PFS).

Results: The median PFS (mPFS) for pyrotinib-based therapy was 12.0 months (95\% Cl 8.1-17.8) in all patients. Among the 44 patients with liver metastases, mPFS was 8.7 months ( $95 \% \mathrm{Cl} 6.3-15.4)$, compared to 12.3 months $(95 \% \mathrm{Cl} 8.8-23.3)$ for the 97 patients without liver metastases $(P=0.172)$. In addition, patients receiving pyrotinib-based therapy as their $>2$ lines treatment had a numerically lower mPFS than those receiving pyrotinib-based therapy as their $\leq 2$ lines treatment (8.4 vs. 15.1 months, $\mathrm{P}=0.107)$. The mPFS was 12.2 months $(95 \% \mathrm{Cl} 7.9-18.8)$ in patients with previous exposure to trastuzumab and 11.8 months $(95 \% \mathrm{Cl} 6.8-22.9)$ in patients without previous exposure to trastuzumab $(\mathrm{P}=0.732)$. Moreover, $\mathrm{mPFS}$ in patients receiving regimens with and without capecitabine were 15.1 months $(95 \% \mathrm{Cl} 10.0-18.8)$ and 8.4 months $(95 \% \mathrm{Cl} 6.7-22.9)$, respectively $(P=0.070)$. Furthermore, in patients with brain metastases, estimated 6-month PFS rate was $70.0 \%$, and rate at 12 months was $60.0 \%$. Seventy patients with measurable lesions were evaluable for response. The ORR was $38.57 \%$ and DCR was $85.71 \%$. Most common adverse event was diarrhea (85.04\%).

Conclusion: Pyrotinib-based therapy showed promising efficacy in patients with HER2-positive breast cancer and was well tolerated, especially in patients treated with pyrotinib as $\leq 2$ lines treatment and receiving regimens with capecitabine. The results of the real-world study further confirmed the intriguing efficacy of pyrotinib.

\section{Introduction}

Breast cancer is one of the most commonly diagnosed malignancy worldwide. Due to lifestyle changes, the incidence of breast cancer is rising in women [1]. With the development of early detection and efficient therapies, mortality from breast cancer has decreased. Nevertheless, breast cancer remains an important cause of death [2,3]. Human epidermal growth factor receptor 2 (HER2)-positive is a key oncogenic driver event, with pathogenesis mainly being the activation of the PI3K/AKt and MAPK pathways [4].

Overexpression of human epidermal growth factor receptor 2 (HER2) occurs in $15 \%-20 \%$ of breast cancer [5].

HER2-positive breast cancer was aggressive, resulting in a poorer prognosis [6, 7]. The anti-HER2 agents, such as trastuzumab, pertuzumab, lapatinib, and adotrastuzumab emtansine (TDM1), have dramatically improved the survival in patients with HER2-positive breast cancer [8, 9]. However, drug resistance remains a major challenge $[10,11]$. Thus, the continued development of novel therapies is required. 
Pyrotinib is a newly-developed irreversible pan-ErbB receptor tyrosine kinase inhibitor inhibiting HER1, HER2, and HER4 [12]. In an open-label phase II study, pyrotinib plus capecitabine had significantly longer progression-free survival (PFS) (18.1 months vs. 7.0 months, $p<0.001)$ and higher objective response rate (ORR) $(78.5 \%$ vs. $57.1 \%, p<0.05)$ than lapatinib plus capecitabine in patients with HER2+ breast cancer [13]. In addition, a randomized Phase III trial (PHOEBE) enrolled 267 patients previously treated with trastuzumab. The results showed that median PFS was significantly longer in patients receiving pyrotinib plus capecitabine than in those receiving lapatinib plus capecitabine ( 12.5 months vs 6.8 months, $\mathrm{P}<0.0001)$, and objective response rate (ORR) was higher for patients treated with pyrotinib plus capecitabine than those treated with lapatinib plus capecitabine $(67.2 \%$ vs $51.5 \%)$. The most common adverse event was diarrhea which was well manageable [14]. Several randomized trials showed the promising efficacy of pyrotinib in HER2+ breast cancer. However, the efficacy of pyrotinib in patients with different baseline characteristics in the actual clinical practice was rarely reported.

This multicenter study analyzed the real-world data of women treated with pyrotinib-based therapy, aiming to describe their characteristics, treatment regimens, and to investigate the clinical outcomes.

\section{Patients And Methods}

\section{Study Design, Treatment, and Assessment}

This was a multicenter, prospective, real-world study conducted at 15 hospitals in China. A total of 141 patients with HER2-positive breast cancer were enrolled from February 2019 to April 2020. Last follow-up time was February 2021. All patients were treated with pyrotinib-based therapy in 21-day cycles. Starting dose was determined by physicians' choice and collected in the Case Report Form (CRF). This study was approved by the Ethics Board of Jiangsu Cancer Hospital (No. 2019-019) and performed in accordance with the Declaration of Helsinki. Written informed consents were obtained from all patients. This trial was registered with Chinese Clinical Trial Registry (ChiCTR1900021819, 11/3/2019).

\section{Patient Population}

Patients were eligible if they were aged $\geq 18$ years and pathologically confirmed advanced HER2-positive breast cancer. HER2 status was evaluated on the basis of ASCO/CAP guidelines [15]. Patients were excluded if they (i) were pregnant or breastfeeding, (ii) had been previously treated with pyrotinib, (iii) lost information of treatment, (iv) received less than one cycle of treatment with pyrotinib. No limits on prior therapy were required.

\section{Study End Points}

The primary endpoint was progression-free survival (PFS), which was calculated as the time from the beginning of treatment with pyrotinib to confirmed disease progression or death. The secondary endpoint included objective response rate (ORR), and disease control rate (DCR) and overall survival (OS). Tumor response assessments were conducted according to Response Evaluation Criteria in Solid Tumors 
(RECIST, version 1.1). Safety assessments were performed using Common Terminology Criteria for Adverse Events (CTCAE, version 5.0).

\section{Statistical Analyses}

Patient characteristics, treatment regimens and starting dosages of pyrotinib were summarized as frequency count (percentage) or median (range). Median PFS was tested by the Kaplan-Meier method. Analyses were performed using STATA statistical software version 15.1 or MedCalc version 18.2.1. $P<0.05$ was considered statistically significant.

\section{Results}

\section{Baseline characteristics}

A total of 141 patients were included from February 2019 to April 2020. Baseline characteristics were showed in Table 1. Median age was 52 (range 29-78 years). One hundred and thirty-six patients (96.45\%) had Eastern Cooperative Oncology Group (ECOG) performance status score <2. Hormone receptor (HR)-positive was present in $56.03 \%$ of the patients. The metastatic sites were in brain (14.89\%), liver $(31.21 \%)$, bone $(43.97 \%)$ and lung (54.61\%). Trastuzumab was previously administered in the (neo)adjuvant setting, metastatic setting, and both (neo)adjuvant setting and metastatic setting to 54(43.55\%), 88(70.97\%), and 18(14.52\%) patients, respectively. Patients with primary trastuzumabresistant breast cancer was $12.10 \%$ (Table1).

\section{Treatment administration}

One hundred and four (73.76\%) patients received pyrotinib-based therapy as the second or further line of treatment (Table 2). One hundred (70.92\%) patients initiated pyrotinib treatment at $400 \mathrm{mg}$. Thirty-nine (27.66\%) patients started with $320 \mathrm{mg}$, and $2(1.42 \%)$ patients had a starting dose of $160 \mathrm{mg}$ (Table 2). The patients received the treatment regimens with capecitabine (55.32\%), trastuzumab (17.73\%), and endocrine therapy, radiotherapy or antiangiogenic drugs (3.55\%) (Table 2). Only 11 (7.80\%) patients were treated with single agent (Table 2).

\section{Efficacy}

At the time of analysis in February 2021, fifty-eight (41.13\%) patients were still receiving pyrotinib. The median PFS (mPFS) for pyrotinib-based therapy was 12.0 months ( $95 \% \mathrm{Cl}$ 8.1-17.8) in all patients (Figure 1). Subgroup analyses were conducted according to brain metastasis, liver metastasis, the lines of systematic therapy of pyrotinib, prior exposure to trastuzumab, and regimen with capecitabine. Among the 44 patients with liver metastases, mPFS was 8.7 months $(95 \% \mathrm{Cl} 6.3-15.4)$, compared to 12.3 months (95\% Cl 8.8-23.3) for the 97 patients without liver metastases ( $P=0.172)$ (Figure 2). In addition, patients receiving pyrotinib-based therapy as their $>2$ lines treatment had a numerically lower mPFS than those receiving pyrotinib-based therapy as their $\leq 2$ lines treatment (8.4 vs. 15.1 months, $P=0.107$ ) (Figure 3 ). The mPFS was 12.2 months $(95 \% \mathrm{Cl} 7.9-18.8)$ in patients with previous exposure to trastuzumab and 11.8 
months $(95 \% \mathrm{Cl} 6.8-22.9)$ in patients without previous exposure to trastuzumab ( $P=0.732)$ (Figure 4). Moreover, mPFS in patients receiving regimens with and without capecitabine were 15.1 months $(95 \% \mathrm{Cl}$ 10.0-18.8) and 8.4 months $(95 \% \mathrm{Cl} 6.7-22.9)$, respectively $(\mathrm{P}=0.070)$ (Figure 5). Furthermore, in patients with brain metastases, estimated 6-month PFS rate was $70.0 \%$, and rate at 12 months was $60.0 \%$ (Figure 6). As of data cutoff, mOS has not yet been reached.

Seventy patients with measurable lesions were evaluable for response. The ORR was $38.57 \%$ and DCR was $85.71 \% .1(1.43 \%)$ patient achieved complete response (CR) and $26(37.14 \%)$ patients had partial response (PR). Thirty-three (47.14\%) patients achieved stable disease (SD) and 10 (14.29\%) patients had progression disease (PD) (Table 3). Subgroup analyses based on brain metastasis, liver metastasis, the lines of systematic therapy of pyrotinib, prior exposure to trastuzumab, and regimen with capecitabine are shown in Table 4.

\section{Safety}

One hundred and twenty-seven patients were included in the safety assessments. The adverse events (AEs) of all grades and grade $\geq 3$ were reported in 123 patients $(96.85 \%)$ and 14 patients $(11.02 \%)$, respectively (Table 5). The most common AE was diarrhea (85.04\%), but only 6 patients $(4.72 \%)$ reported Grade $\geq 3$ diarrhea. Moreover, the AEs of all grades that were documented in $\geq 15 \%$ of patients included anemia (37.01\%), leukopenia (24.6\%), vomiting (24.41\%), neutropenia $(22.22 \%)$, and hyperbilirubinemia $(17.32 \%)$. No treatment-related deaths were reported. Overall, the safety of pyrotinib-based therapy was controllable and tolerable.

\section{Discussion}

HER2-positive breast cancer is a more aggressive phenotype [16]. The anti-HER2 agents (trastuzumab, pertuzumab, lapatinib, and TDM1) have dramatically improved the prognosis in patients with HER2positive breast cancer [17]. However, primary or acquired resistance to anti-HER2 agents remains a major challenge [10]. Thus, the novel therapy is required to provide option to patients.

This study was carried out to analyze the efficacy and safety of pyrotinib-based therapy in patients with HER2-positive breast cancer in the real world. The most inspiring result of the study was a mPFS of 12.0 months, higher than that of trastuzumab (10.9 months) and TDM1(10.0 months) in real-world setting [18, 19], and close to the mPFS result (12.5 months) of pyrotinib in previous phase III trial (PHOEBE) [14]. In addition, the ORR of pyrotinib-based therapy in this study was $38.57 \%$ was also superior to that of TDM1 (20.0\%) [20].

Subgroup results confirmed that the mPFS in patients with liver metastases was 8.7 months, which was shorter than the 12.3 months found in patients without liver metastases. This result is concordant with previous report in which liver metastases correlated with worse survival in patients with breast cancer [21,22]. Moreover, the mPFS was 15.1 months in patients receiving pyrotinib as $\leq 2$ lines treatment, similar to the result of trastuzumab as first-line treatment reported in PUFFIN study (14.5 months) [23]. 
Our study demonstrated the efficacy of pyrotinib, providing evidence for the patients treated with pyrotinib as $\leq 2$ lines treatment. In addition, $87.94 \%$ patients in our study received prior trastuzumab treatment, thus we assessed the benefit of pyrotinib-based therapy in patients progressed on trastuzumab. The results showed that patients could benefit from pyrotinib, regardless of whether they had been previously exposed to trastuzumab or not. Our results also confirmed that pyrotinib-based therapy with capecitabine achieved a numerically higher ORR and longer MPFS than that without capecitabine, which merits further assessment in the future. In addition, among patients with brain metastases, the 6-month and 12-month PFS rates were $70.0 \%$ and $60.0 \%$, respectively, numerically better than that of anti-HER2 monoclonal antibodies in patients with brain metastases [18, 24, 25], indicating that pyrotinib is an important treatment option for patients with brain metastases.

Diarrhea was the most common AE (85.04\%), but only $4.72 \%$ patients were reported grade $\geq 3$ diarrhea which could be well controlled. The incidence of diarrhea in our study was lower than that in previously studies of pyrotinib $[14,26]$, which may be the result of the relatively low dose of pyrotinib (only $70.92 \%$ of patients were treated with pyrotinib at a starting dose of $400 \mathrm{mg} /$ day). The antidiarrhea treatment or dose reduction after diarrhea could well control the occurrence of diarrhea.

This study confirmed the advantages of pyrotinib. However, the data were acquired from an observational study which included potential information bias or incomplete data. In addition, mOS has not yet been reached. Despite these limitations, the results of this study provide evidence for the real-world use of pyrotinib in patients with HER2-positive breast cancer.

In conclusion, pyrotinib-based therapy showed promising efficacy in patients with HER2-positive breast cancer and was well tolerated, especially in patients treated with pyrotinib as $\leq 2$ lines treatment and receiving regimens with capecitabine. The results of the real-world study further confirmed the intriguing efficacy of pyrotinib.

\section{References}

1. Harbeck N, Gnant M. Breast cancer. Lancet. 2017; 389(10074):1134-1150. doi: 10.1016/s01406736(16)31891-8.

2. McDonald ES, Clark AS, Tchou J, Zhang P, Freedman GM. Clinical Diagnosis and Management of Breast Cancer. J Nucl Med. 2016; 57 Suppl 1:9s-16s. doi: 10.2967/jnumed.115.157834.

3. Abderrahman B, Jordan VC. Successful Targeted Therapies for Breast Cancer: the Worcester Foundation and Future Opportunities in Women's Health. Endocrinology. 2018; 159(8):2980-2990. doi: 10.1210/en.2018-00263.

4. D'Amato V, Raimondo L, Formisano L, Giuliano M, De Placido S, Rosa R, Bianco R. Mechanisms of lapatinib resistance in HER2-driven breast cancer. Cancer Treat Rev. 2015; 41(10):877-883. doi: 10.1016/j.ctrv.2015.08.001. 
5. Slamon DJ, Godolphin W, Jones LA, Holt JA, Wong SG, Keith DE, Levin WJ, Stuart SG, Udove J, Ullrich A, et al. Studies of the HER-2/neu proto-oncogene in human breast and ovarian cancer. Science. 1989; 244(4905):707-712. doi: 10.1126/science.2470152.

6. LoibI S, Gianni L. HER2-positive breast cancer. Lancet. 2017; 389(10087):2415-2429. doi: 10.1016/s0140-6736(16)32417-5.

7. Waks AG, Winer EP. Breast Cancer Treatment: A Review. Jama. 2019; 321(3):288-300. doi: 10.1001/jama.2018.19323.

8. Swain SM, Baselga J, Kim SB, Ro J, Semiglazov V, Campone M, Ciruelos E, Ferrero JM, Schneeweiss A, Heeson S, Clark E, Ross G, Benyunes MC, Cortés J. Pertuzumab, trastuzumab, and docetaxel in HER2-positive metastatic breast cancer. N Engl J Med. 2015; 372(8):724-734. doi: 10.1056/NEJMoa1413513.

9. Diéras V, Miles D, Verma S, Pegram M, Welslau M, Baselga J, Krop IE, Blackwell K, Hoersch S, Xu J, Green M, Gianni L. Trastuzumab emtansine versus capecitabine plus lapatinib in patients with previously treated HER2-positive advanced breast cancer (EMILIA): a descriptive analysis of final overall survival results from a randomised, open-label, phase 3 trial. Lancet Oncol. 2017; 18(6):732742. doi: 10.1016/s1470-2045(17)30312-1.

10. Vernieri C, Milano M, Brambilla M, Mennitto A, Maggi C, Cona MS, Prisciandaro M, Fabbroni C, Celio L, Mariani G, Bianchi GV, Capri G, de Braud F. Resistance mechanisms to anti-HER2 therapies in HER2-positive breast cancer: Current knowledge, new research directions and therapeutic perspectives. Crit Rev Oncol Hematol. 2019; 139:53-66. doi: 10.1016/j.critrevonc.2019.05.001.

11. Sung M, Tan X, Lu B, Golas J, Hosselet C, Wang F, Tylaska L, King L, Zhou D, Dushin R, Myers JS, Rosfjord E, Lucas J, Gerber HP, Loganzo F. Caveolae-Mediated Endocytosis as a Novel Mechanism of Resistance to Trastuzumab Emtansine (T-DM1). Mol Cancer Ther. 2018; 17(1):243-253. doi: 10.1158/1535-7163.mct-17-0403.

12. Li X, Yang C, Wan H, Zhang G, Feng J, Zhang L, Chen X, Zhong D, Lou L, Tao W, Zhang L. Discovery and development of pyrotinib: A novel irreversible EGFR/HER2 dual tyrosine kinase inhibitor with favorable safety profiles for the treatment of breast cancer. Eur J Pharm Sci. 2017; 110:51-61. doi: 10.1016/j.ejps.2017.01.021.

13. Ma F, Ouyang Q, Li W, Jiang Z, Tong Z, Liu Y, Li H, Yu S, Feng J, Wang S, Hu X, Zou J, Zhu X, Xu B. Pyrotinib or Lapatinib Combined With Capecitabine in HER2-Positive Metastatic Breast Cancer With Prior Taxanes, Anthracyclines, and/or Trastuzumab: A Randomized, Phase II Study. J Clin Oncol. 2019; 37(29):2610-2619. doi: 10.1200/jco.19.00108.

14. Xu B, Yan M, Ma F, Hu X, Feng J, Ouyang Q, Tong Z, Li H, Zhang Q, Sun T, Wang X, Yin Y, Cheng Y, Li W, Gu Y, Chen Q, Liu J, Cheng J, Geng C, Qin S, Wang S, Lu J, Shen K, Liu Q, Wang X, Wang H, Luo T, Yang J, Wu Y, Yu Z, Zhu X, Chen C, Zou J. Pyrotinib plus capecitabine versus lapatinib plus capecitabine for the treatment of HER2-positive metastatic breast cancer (PHOEBE): a multicentre, open-label, randomised, controlled, phase 3 trial. Lancet Oncol. 2021; 22(3):351-360. doi: 10.1016/s1470-2045(20)30702-6. 
15. Wolff AC, Hammond ME, Hicks DG, Dowsett M, McShane LM, Allison KH, Allred DC, Bartlett JM, Bilous M, Fitzgibbons P, Hanna W, Jenkins RB, Mangu PB, Paik S, Perez EA, Press MF, Spears PA, Vance GH, Viale G, Hayes DF. Recommendations for human epidermal growth factor receptor 2 testing in breast cancer: American Society of Clinical Oncology/College of American Pathologists clinical practice guideline update. J Clin Oncol. 2013; 31(31):3997-4013. doi:

10.1200/jco.2013.50.9984.

16. Slamon DJ, Clark GM, Wong SG, Levin WJ, Ullrich A, McGuire WL. Human breast cancer: correlation of relapse and survival with amplification of the HER-2/neu oncogene. Science. 1987; 235(4785):177-182. doi: 10.1126/science.3798106.

17. Cesca MG, Vian L, Cristóvão-Ferreira S, Pondé N, de Azambuja E. HER2-positive advanced breast cancer treatment in 2020. Cancer Treat Rev. 2020; 88:102033. doi: 10.1016/j.ctrv.2020.102033.

18. Hardy-Werbin M, Quiroga V, Cirauqui B, Romeo M, Felip E, Teruel I, Garcia JJ. Real-world data on TDM1 efficacy - results of a single-center retrospective study of HER2-positive breast cancer patients. 2019; 9(1):12760. doi: 10.1038/s41598-019-49251-5.

19. Li Y, Gong C, Lu Q, Zhou Z, Luo T, Li W, Li G, Ge R, Xu F, Wang B. Real-World Data of Triplet Combination of Trastuzumab, Lapatinib, and Chemotherapy in HER2-Positive Metastatic Breast Cancer: A Multicenter Retrospective Study. Front Oncol. 2020; 10:271. doi: 10.3389/fonc.2020.00271.

20. Li F, Xu F, Li J, Wang T, Bian L, Zhang S, Jiang Z. Pyrotinib versus trastuzumab emtansine for HER2positive metastatic breast cancer after previous trastuzumab and lapatinib treatment: a real-world study. Ann Transl Med. 2021; 9(2):103. doi: 10.21037/atm-20-4054.

21. Cameron D, Casey M, Oliva C, Newstat B, Imwalle B, Geyer CE. Lapatinib plus capecitabine in women with HER-2-positive advanced breast cancer: final survival analysis of a phase III randomized trial. Oncologist. 2010; 15(9):924-934. doi: 10.1634/theoncologist.2009-0181.

22. Göksu SS, Bozcuk H, Koral L, Çakar B, Gündüz S, Tatlı AM, Arslan D, Uysal M, Koçer M, Artaç M, Karabulut B, Coşkun HS, Özdoğan M, Savaş B. Factors predicting lapatinib efficacy in HER-2+ metastatic breast carcinoma: Does it work better in different histologic subtypes? Indian J Cancer. 2015; 52(4):517-519. doi: 10.4103/0019-509x.178382.

23. Xu B, Li W, Zhang Q, Shao Z, Li Q, Wang X, Li H, Sun T, Yin Y, Zheng H, Feng J, Zhang H, Lei G, Restuccia E. Pertuzumab, trastuzumab, and docetaxel for Chinese patients with previously untreated HER2-positive locally recurrent or metastatic breast cancer (PUFFIN): a phase III, randomized, doubleblind, placebo-controlled study. Breast Cancer Res Treat. 2020; 182(3):689-697. doi: 10.1007/s10549020-05728-w.

24. Krop IE, Lin NU, Blackwell K, Guardino E, Huober J, Lu M, Miles D, Samant M, Welslau M, Diéras V. Trastuzumab emtansine (T-DM1) versus lapatinib plus capecitabine in patients with HER2-positive metastatic breast cancer and central nervous system metastases: a retrospective, exploratory analysis in EMILIA. Ann Oncol. 2015; 26(1):113-119. doi: 10.1093/annonc/mdu486. 
25. Lin NU, Borges V, Anders C, Murthy RK, Paplomata E, Hamilton E, Hurvitz S, Loi S, Okines A, Abramson V, Bedard PL, Oliveira M, Mueller V, Zelnak A, DiGiovanna MP, Bachelot T, Chien AJ, O'Regan R, Wardley A, Conlin A, Cameron D, Carey L, Curigliano G, Gelmon K, Loibl S, Mayor J, McGoldrick S, An X, Winer EP. Intracranial Efficacy and Survival With Tucatinib Plus Trastuzumab and Capecitabine for Previously Treated HER2-Positive Breast Cancer With Brain Metastases in the HER2CLIMB Trial. J Clin Oncol. 2020; 38(23):2610-2619. doi: 10.1200/jco.20.00775.

26. Ma F, Li Q, Chen S, Zhu W, Fan Y, Wang J, Luo Y, Xing P, Lan B, Li M, Yi Z, Cai R, Yuan P, Zhang P, Li Q, Xu B. Phase I Study and Biomarker Analysis of Pyrotinib, a Novel Irreversible Pan-ErbB Receptor Tyrosine Kinase Inhibitor, in Patients With Human Epidermal Growth Factor Receptor 2-Positive Metastatic Breast Cancer. J Clin Oncol. 2017; 35(27):3105-3112. doi: 10.1200/jco.2016.69.6179.

\section{Tables}

Table 1. Patient characteristics at baseline 


\begin{tabular}{|ll|}
\hline Characteristic & No. of patients (\%) (n=141) \\
\hline Age, median (range, $y r)$ & $52(29-78)$ \\
\hline ECOG performance status & \\
\hline$<2$ & $136(96.45)$ \\
\hline$\geq 2$ & $5(3.55)$ \\
\hline Hormone receptor status & \\
\hline HR positive & $79(56.03)$ \\
\hline HR negative & $61(43.26)$ \\
\hline Unknown & $1(0.71)$ \\
\hline Metastatic sites & \\
\hline Brian & $21(14.89)$ \\
\hline Liver & $44(31.21)$ \\
\hline Bone & $62(43.97 \varnothing$ \\
\hline Lung & $77(54.61)$ \\
\hline Previous trastuzumab therapy & $124(87.94)$ \\
\hline For advanced disease & $88(70.97)$ \\
\hline As neo/adjuvant therapy & $54(43.55)$ \\
\hline Both & $18(14.52)$ \\
\hline Primary resistance to trastuzumab* & $15(12.10)$ \\
\hline
\end{tabular}

*Primary resistance to trastuzumab was defined as relapse during or within 12 months after adjuvant trastuzumab or progression within 3 months of trastuzumab treatment for metastatic disease.

Table 2. Treatment administration 


\begin{tabular}{|ll|}
\hline Pyrotinib treatment & No. of patients (\%) (n=141) \\
\hline Lines of systematic therapy of pyrotinib for ABC/MBC & \\
\hline 1 & $37(26.24)$ \\
\hline Starting dosage of Pyrotinib (mg/day) & $104(73.76)$ \\
\hline $400 m g$ & $100(70.92)$ \\
\hline $320 m g$ & $39(27.66)$ \\
\hline $160 m g$ & $2(1.42)$ \\
\hline Regimens & \\
\hline Regimens with capecitabine & $78(55.32)$ \\
\hline Pyrotinib + capetabine & $69(88.46)$ \\
\hline Pyrotinib + capetabine + paclitaxel & $1(1.28)$ \\
\hline Pyrotinib + capetabine + trastuzumab & $8(10.26)$ \\
\hline Regimens with trastuzumab & $25(17.73)$ \\
\hline Pyrotinib + trastuzumab + chemotherapy & $18(72.00)$ \\
\hline Pyrotinib + trastuzumab + pertuzumab + chemotherapy & $1(4.00)$ \\
\hline Pyrotinib + trastuzumab & $4(16.00)$ \\
\hline Pyrotinib + trastuzumab + endocrine therapy & $2(8.00)$ \\
\hline Pyrotinib & $11(7.80)$ \\
\hline Pyrotinib + endocrine therapy & $2(1.42)$ \\
\hline Pyrotinib + radiotherapy & $2(1.42)$ \\
\hline Pyrotinib + antiangiogenic drug & $1(0.71)$ \\
\hline
\end{tabular}

Abbreviations: $\mathrm{ABC}$, advanced breast cancer; $\mathrm{MBC}$, metastatic breast cancer.

Table 3. Objective response rate in 70 patients with measurable lesions at baseline 


\begin{tabular}{|ll|}
\hline Best response & No. of patients $(\%)(\mathbf{n}=\mathbf{7 0})$ \\
\hline CR & $1(1.43)$ \\
\hline PR & $26(37.14)$ \\
\hline SD & $33(47.14)$ \\
\hline PD & $10(14.29)$ \\
\hline ORR & $27(38.57)$ \\
\hline DCR & $60(85.71)$ \\
\hline
\end{tabular}

Table 4. The subgroup analyses of the objective response rate

\begin{tabular}{|c|c|c|}
\hline Best response & ORR (\%) & DCR (\%) \\
\hline \multicolumn{3}{|c|}{ Brain metastasis } \\
\hline Yes & 45.45 & 90.91 \\
\hline No & 37.29 & 84.75 \\
\hline \multicolumn{3}{|c|}{ Liver metastasis } \\
\hline Yes & 39.13 & 86.96 \\
\hline No & 38.30 & 85.11 \\
\hline \multicolumn{3}{|c|}{ Lines of systematic therapy of pyrotinib } \\
\hline$>2$ & 32.35 & 79.41 \\
\hline$\leq 2$ & 44.44 & 91.67 \\
\hline \multicolumn{3}{|c|}{ Prior exposure to trastuzumab } \\
\hline Yes & 36.07 & 85.25 \\
\hline No & 50.00 & 87.50 \\
\hline \multicolumn{3}{|c|}{ Regimen with capecitabine } \\
\hline Yes & 35.29 & 85.29 \\
\hline No & 33.33 & 86.67 \\
\hline
\end{tabular}

Table 5. Adverse events 


\begin{tabular}{|lll|}
\hline Adverse event & All Grade & Grade $\geq 3$ \\
\hline Diarrhea & $85.04 \%$ & $4.72 \%$ \\
\hline Anemia & $37.01 \%$ & $0.00 \%$ \\
\hline Leukopenia & $24.60 \%$ & $0.00 \%$ \\
\hline Vomiting & $24.41 \%$ & $0.79 \%$ \\
\hline Neutropenia & $22.22 \%$ & $2.38 \%$ \\
\hline Hyperbilirubinemia & $17.32 \%$ & $3.15 \%$ \\
\hline Aspartate aminotransferase increased & $11.81 \%$ & $0.79 \%$ \\
\hline Alkaline phosphatase increased & $11.81 \%$ & $0.79 \%$ \\
\hline Y-glutamyltransferase increased & $11.02 \%$ & $1.58 \%$ \\
\hline Thrombocytopenia & $9.52 \%$ & $0.00 \%$ \\
\hline Rash & $9.45 \%$ & $1.57 \%$ \\
\hline Hypoalbuminemia & $9.45 \%$ & $0.79 \%$ \\
\hline Alanine aminotransferase increased & $9.45 \%$ & $0.00 \%$ \\
\hline Nausea & $7.87 \%$ & $0.00 \%$ \\
\hline Asthenia & $5.51 \%$ & $0.00 \%$ \\
\hline Stomatitis & $4.72 \%$ & $0.00 \%$ \\
\hline Decreased appetite & $4.72 \%$ & $0.00 \%$ \\
\hline Hand-foot syndrome & $1.57 \%$ & $0.00 \%$ \\
\hline Paronychia & $1.57 \%$ & $0.00 \%$ \\
\hline Kidney function abnormalities & $1.57 \%$ & $0.00 \%$ \\
\hline Abdominal pain & $0.79 \%$ & $0.00 \%$ \\
\hline Palpitation & $0.79 \%$ & $0.00 \%$ \\
\hline Dizziness & $0.79 \%$ & $0.00 \%$ \\
\hline Pruritus & $0.79 \%$ & $0.00 \%$ \\
\hline
\end{tabular}

Figures 


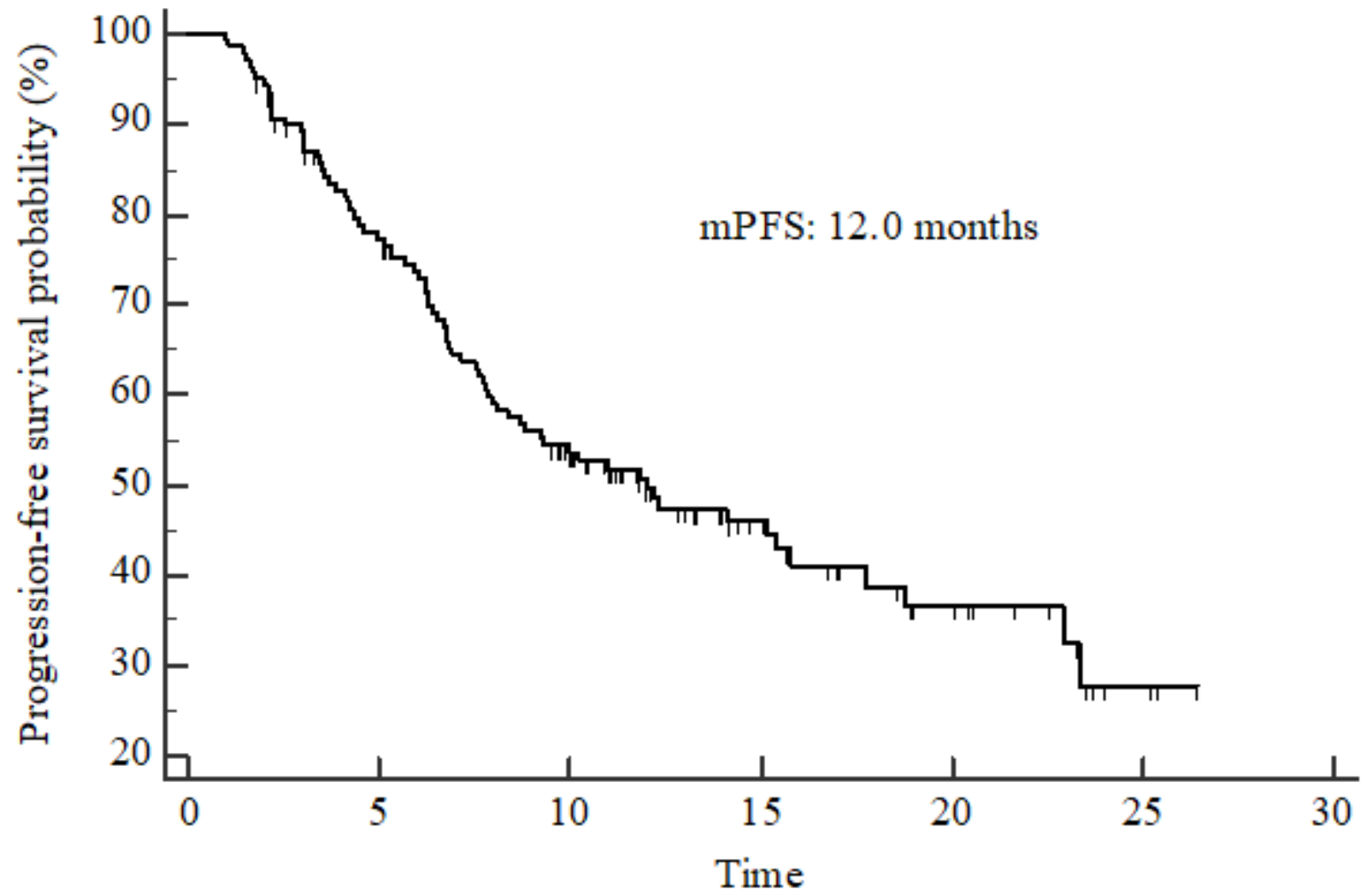

Number at risk

$\begin{array}{lllllll}141 & 104 & 64 & 30 & 14 & 3 & 0\end{array}$

Figure 1

Kaplan-Meier estimates of PFS for all patients treated with pyrotinib-based therapy 


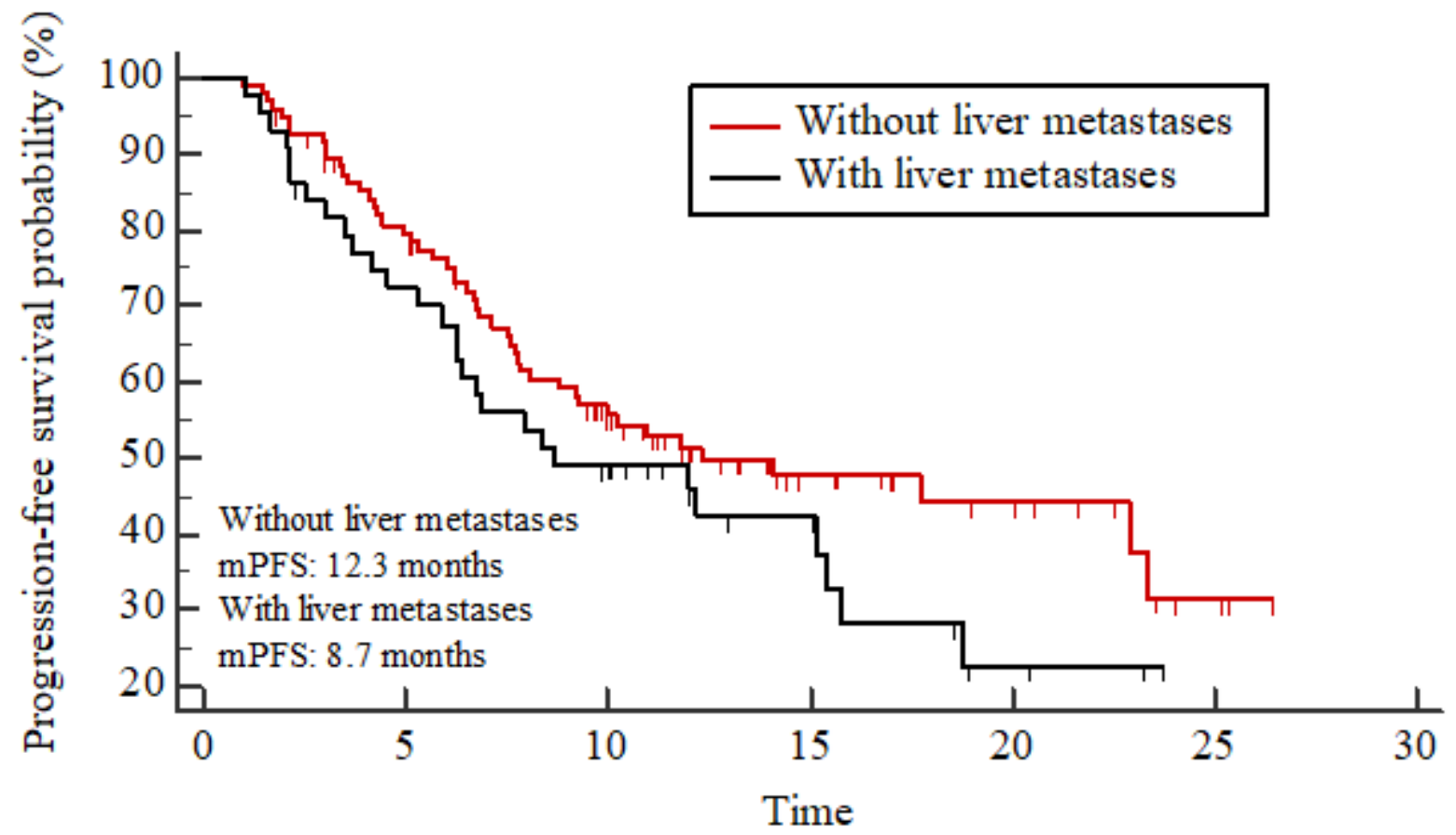

Number at risk

Without liver metastases

$\begin{array}{lllllll}97 & 73 & 44 & 19 & 11 & 3 & 0\end{array}$

With liver metastases

$\begin{array}{lllllll}44 & 31 & 20 & 11 & 3 & 0 & 0\end{array}$

Figure 2

Kaplan-Meier estimates of PFS for patients with and with and without liver metastases 


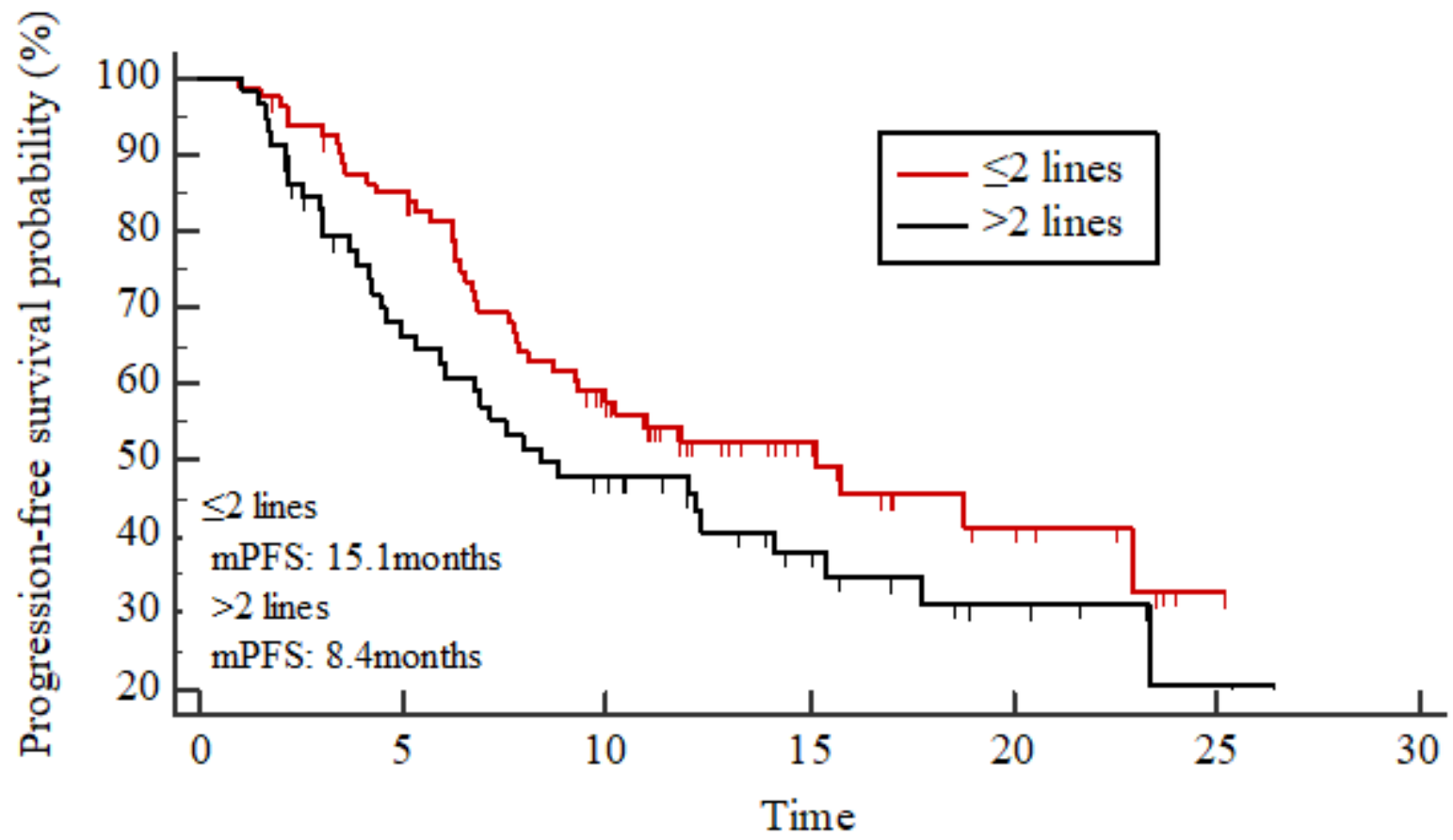

Number at risk

$\leq 2$ lines

\begin{tabular}{|c|c|c|c|c|c|}
\hline 82 & 68 & 39 & 17 & 8 & 1 \\
\hline$>2$ lines & & & & & \\
\hline 59 & 36 & 25 & 13 & 6 & 2 \\
\hline
\end{tabular}

Figure 3

Kaplan-Meier estimates of PFS for patients stratified by treatment lines 


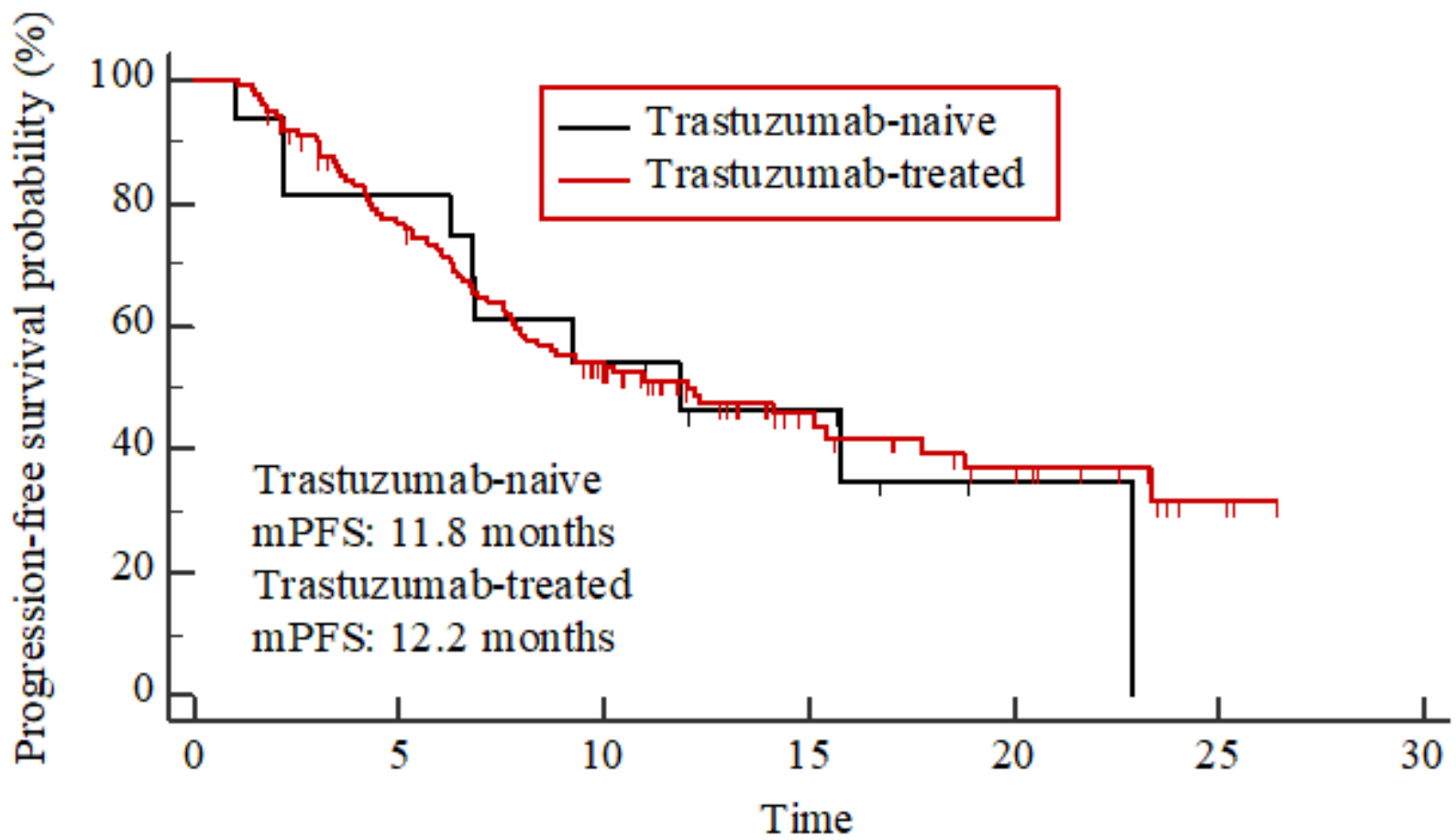

Number at risk

Trastuzumab-naive

$16 \quad 13$

Trastuzumab-treated

$124 \quad 90$

85

1

0

0

56

25

13

3

0

Figure 4

Kaplan-Meier estimates of PFS for patients with and without prior trastuzumab exposure 


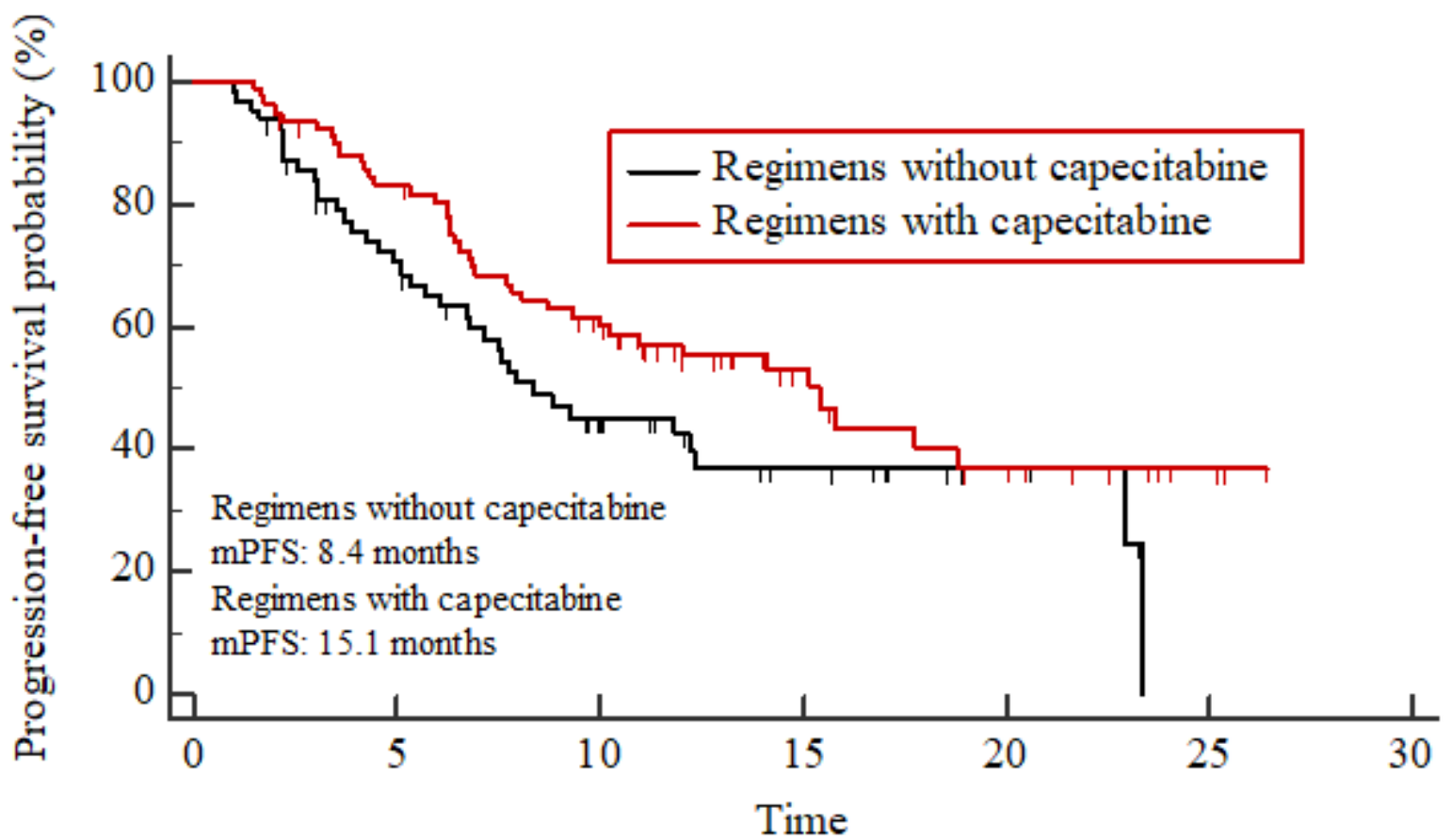

Number at risk

Regimens without capecitabine

$63 \quad 41 \quad 22$

Regimens with capecitabine

$\begin{array}{lll}78 & 63 & 42\end{array}$

42

11

4

0

0

19

10

3

0

Figure 5

Kaplan-Meier estimates of PFS for patients receiving regimens with and without capecitabine 


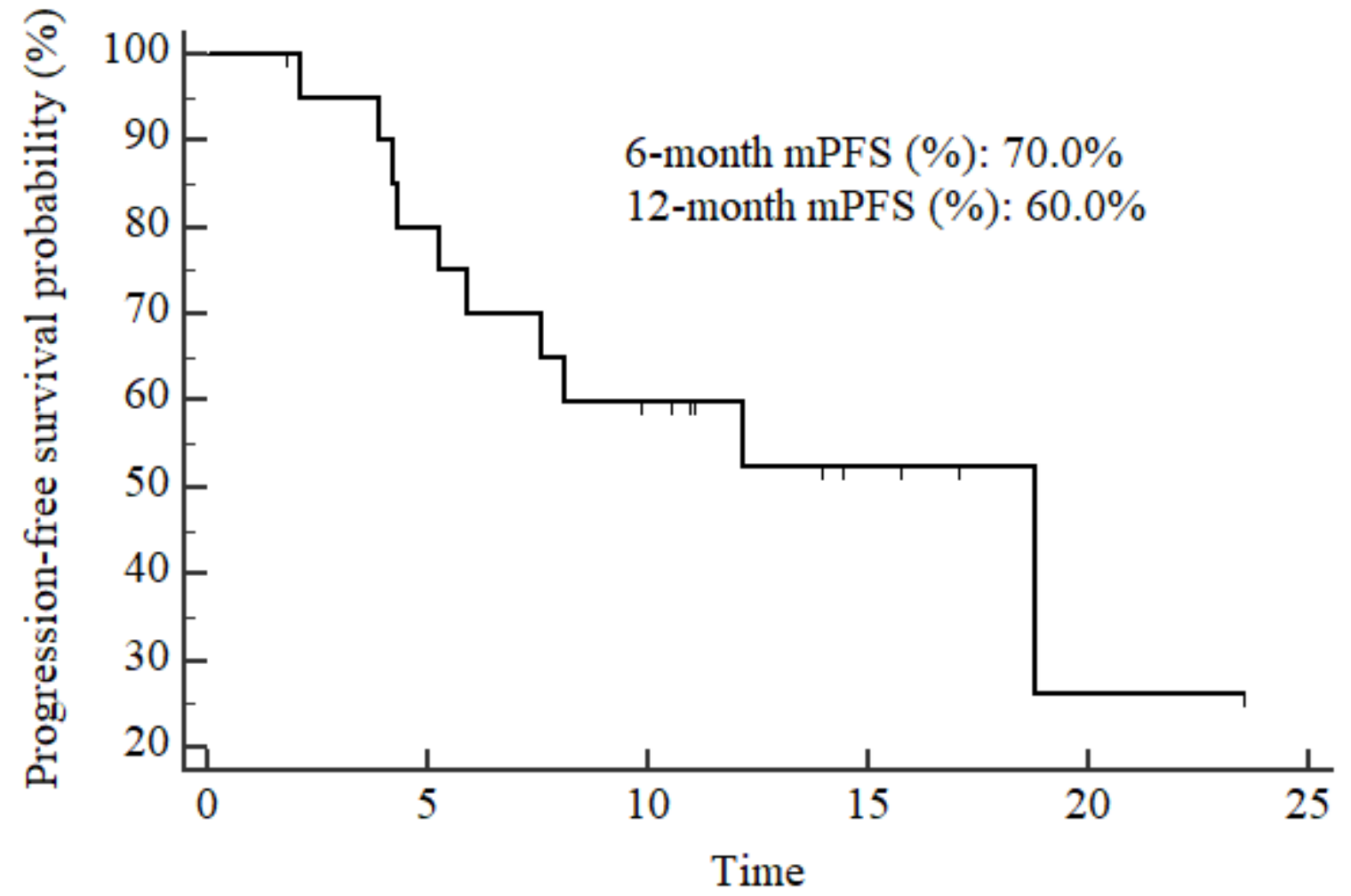

Number at risk

21

16

11

4

1

0

Figure 6

Kaplan-Meier estimates of PFS for patients with brain metastases 